\title{
Erratum: Will PI3K pathway inhibitors be effective as single agents in patients with cancer?
}

\author{
Joan T. Garrett ${ }^{1}$, Anindita Chakrabarty ${ }^{1}$ and Carlos L. Arteaga ${ }^{1,2,3}$ \\ ${ }^{1}$ Department of Medicine, Vanderbilt-Ingram Cancer Center, Vanderbilt University, Nashville, TN, USA \\ 2 Department of Cancer Biology, Vanderbilt-Ingram Cancer Center, Vanderbilt University, Nashville, TN, USA \\ ${ }^{3}$ Breast Cancer Research Program, Vanderbilt-Ingram Cancer Center, Vanderbilt University, Nashville, TN, USA \\ Published: August 17, 2018
}

Copyright: Garrett et al. This is an open-access article distributed under the terms of the Creative Commons Attribution License 3.0 (CC BY 3.0), which permits unrestricted use, distribution, and reproduction in any medium, provided the original author and source are credited.

This article has been corrected: During production, the text of the subsections 'INHIBITION OF P13K IS INCOMPLETE WITH SINGLE AGENTS' and 'CLINICAL IMPLICATIONS' was duplicated within the article. The corrected version now has the duplicated text removed while preserving the original pagination.

Original article: Oncotarget. 2011; 2:1314-1321. https://doi.org/10.18632/oncotarget.409 